\title{
Cost comparison analysis of laparoscopic versus open aortobifemoral bypass surgery: a randomized controlled trial
}

This article was published in the following Dove Press journal: Open Access Journal of Clinical Trials

M Sahba'
AH Krog'
EM Pettersen ${ }^{2}$
T Wisløff
KG Rogne
JO Sundhagen
${ }^{6}$
SSH Kazmi ${ }^{6,7}$
'Department of Vascular Surgery,
Ostfold Central Hospital, Grålum,
Norway; ${ }^{2}$ Department of Vascular
Surgery, Sørlandet Hospital HF,
Kristiansand, Norway; ${ }^{3}$ Department of
Infectious Disease Epidemiology and
Modelling, Norwegian Institute of Public
Health, Oslo, Norway; ${ }^{4}$ Department of
Health Management and Health
Economics, University of Oslo, Oslo,
Norway; ${ }^{5}$ Economy Department, Oslo
University Hospital, Oslo, Norway;
${ }^{6}$ Department of Vascular Surgery,
Division of Cardiovascular and
Pulmonary Diseases, Oslo University
Hospital, Oslo, Norway; ${ }^{7}$ Faculty of
Medicine, Oslo University, Oslo, Norway

Correspondence: M Sahba Department of Vascular Surgery, Ostfold Central Hospital, Kalnesveien 300, Grålum 1714, Norway

Email mehdi.sahba@so-hf.no
Background: Laparoscopic aortobifemoral bypass (LABFB) surgery has become an established treatment procedure for aortoiliac occlusive disease (AIOD), Trans-Atlantic Inter-Society Consensus II (TASC II), type D lesions. However, studies with an economic evaluation of this procedure are sparse. The main purpose of our study was to compare the costs of LABFB and open aortobifemoral bypass (OABFB) surgery.

Patients and methods: This is a substudy of a larger randomized controlled prospective multicenter trial, Norwegian Laparoscopic Aortic Surgery Trial (NLAST). Perioperative data were collected on 70 patients undergoing surgery for AIOD, TASC type D lesions. Thirty-four patients were randomized to LABFB and 36 patients to OABFB. Treatment costs were calculated for the two operative treatments until 30 postoperative days. In addition to fixed and variable costs, direct and indirect costs were also included.

Results: The mean total cost of LABFB was $19,798 €$ and for OABFB 34,016 $€$ until 30 postoperative days. Laparoscopic procedure was $14,218 €$ less costly than the open procedure. The main factor leading to less cost of LABFB was shorter length of hospital stay (mean 5.3 days, 95\% CI 4.1-6.5) as compared to OABFB (mean 10.1 days, 95\% CI 7.5-12.6). Ten patients, three in the LABFB and seven in the OABFB group, had complications that resulted in reoperations within the 30 postoperative days. The mean cost of treatment for the complicated patients was $49,349 €$ and $82,985 €$, respectively, for $\mathrm{LABFB}$ and $\mathrm{OABFB}$.

Conclusion: Laparoscopic aortobifemoral bypass procedure costs less than open aortobifemoral bypass for the treatment of advanced aortoiliac occlusive disease.

Keywords: cost comparison, laparoscopic aortobifemoral bypass, laparoscopic treatment

\section{Introduction}

Open aortobifemoral bypass $(\mathrm{OABFB})$ has been a routine procedure for the treatment of aortoiliac occlusive disease (AIOD). ${ }^{1,2}$ Although endovascular therapy has become the first choice of treatment, even for advanced $\mathrm{AIOD},{ }^{3,4}$ the long-term primary patency of conventional OABFB remains superior. ${ }^{1,5}$ However, patients with an unsuccessful endovascular treatment, patients with atherosclerotic lesion not suitable for endovascular treatment, or young patients with little or no operative risks, are left with the treatment option of conventional aortobifemoral bypass operation. ${ }^{6,7}$ LABFB for the treatment of AIOD claims to provide the benefits of mini-invasive procedure, with the same long-term patency as with the OABFB. ${ }^{8}$ However, LABFB has been criticized for being technically 
demanding. ${ }^{9}$ LABFB has become an established routine treatment alternative to OABFB at dedicated centers. ${ }^{8,10,11}$

During the last two decades, morbidity and mortality had been the main concern in the published literature about the surgical treatment of the AIOD. ${ }^{1}$ However, other aspects related to the treatment, eg, patient-reported outcome measures and economic costs, can also have an important role in decisionmaking for the choice of treatment. The rapid and widespread introduction of laparoscopic technique in different fields of surgery has shown to have implications for health-care costs. ${ }^{12,13}$ The cost of health services will be affected by minimal-access treatment, due to reduced hospital stay and change in operating time, particularly when a new technique is introduced. ${ }^{8}$ The advantages and disadvantages of each new technology need to be evaluated in terms of resources used, in form of equipment, time and administrative costs. ${ }^{14,15}$ Previously, it has been reported that the treatment cost of LABFB is lower than the OABFB procedure. ${ }^{16}$ However, the study had a retrospective design and did not give a full account of the cost estimation and calculations for these procedures.

The main objective of this study was to perform a detailed economic evaluation of the LABFB and OABFB procedures in a randomized setting.

\section{Patients and methods}

\section{Design}

This study is a substudy of an ongoing multicenter, randomized, controlled trial,Norwegian Laparoscopic Aortic Surgery Trial(NLAST). The primary end-point of the NLAST is postoperative complications (systemic and local). The main objective of this substudy was to compare the in-hospital costs of the LABFB and OABFB, during 30 postoperative days. In addition, we aimed to perform separate cost analyses of patients with and without complications.

We used block randomization. Neither patients nor surgeons could be blinded. The randomization sequence was generated on a computer and saved in opaque envelopes. The sequence was unknown and the envelopes were only opened after the patient had given informed written consent. The inclusion and exclusion criteria are presented in Table 1.

The economic costs calculated did not include the outpatient costs. Costs were calculated for the following three phases of the patients stay in hospital:

- Operation theatre costs

- Recovery unit costs

- Costs at the vascular surgery ward

Operation theatre costs were further divided into:

- Fixed costs:

- Personnel

- Technical devices

- Variable costs:

- Re-usable instruments

- Disposable instruments

Costs were considered as direct costs, if they were directly attributed to the patient's care, and the rest of the overhead costs were defined as indirect costs if not attributed to the completion of the treatment, for example, house rent, electricity, IT investments, and kitchen.

Table I Inclusion and exclusion criteria for patients with TASC II type D lesions, treated with either open or laparoscopic aortobifemoral bypass

\begin{tabular}{|l|l|}
\hline Inclusion criteria & Exclusion criteria \\
\hline Patient with AIOD, TASC II type D & $\bullet$ Fit for endovascular procedure \\
and symptoms in form of: & $\bullet$ COPD stage IV, GOLD classification \\
$\bullet \begin{array}{l}\text { Intermittent claudication, with walking distance }<200 \mathrm{~m} \text { and/or } \\
\text { - Chronic critical lower limb ischemia with rest pain or ischemic ulcers }\end{array}$ & $\bullet$ Chronic heart failure, EF $<40 \%$ \\
with duration of symptoms $>2$ weeks & $\bullet$ Active cancer disease \\
& $\bullet$ Hostile abdomen, previous multiple open major abdominal surgeries \\
& - AAA $>3.0 \mathrm{~cm}$ \\
& - Acute critical limb ischemia. Duration of symptoms $<2$ weeks \\
\hline
\end{tabular}

Abbreviations: AAA Abdominal aortic aneurysm; AIOD, aortoiliac occlusive disease; EF, ejection fraction; TASC II, Trans-Atlantic Inter-Society Consensus II; GOLD, Global Initiative for Chronic Obstructive Pulmonary Disease. 
The following formula has been utilized to calculate the price per hour $(\mathrm{Pc})$ for the operation personnel cost. ${ }^{17}$

$$
\operatorname{Pc}=\frac{1}{12} \times \frac{\text { annual salary per year } x 60}{\text { working hours per week } x \text { effective working days per year }}
$$

To avoid double calculations, we included costs of surgeons and anesthesiologists only at their respective units, ie, vascular surgery ward and recovery unit. Time from arrival to discharge from the operation theatre was registered. One-day hospital stay cost at the recovery unit and vascular surgery ward was calculated based on the annual in-hospital days (total patient days) and the annual budgets for the respective departments for 2016. We have grouped together different categories of surgeons and anesthesiologists (consultants and residents). The surgeons and the anesthesiologists were budgeted, respectively, in the vascular surgery ward and recovery unit. The economic data were attained from the hospital economy department for the year 2016. To calculate the indirect cost for the vascular surgery department, we excluded all costs related to personnel salaries.

Time used by the operation nurses and anesthesiology nurses was recorded in detail, and the annual wage tariffs for 2016 for the Norwegian Nurses Association were used for calculation of the costs at the operation theatre. We employed 35.5 working hours per week for nurses in our calculations. We employed the formula described by Ismail et $\mathrm{al}^{17}$ for the calculation of the cost of technical devices:

$$
\mathrm{TC}=\sum_{i=1}^{m} \frac{1}{E i \times N i}\left(P i+M i \times \frac{1-(1+r)^{-E i-1}}{1-(1-r)^{-1}}\right)
$$

where TC, Ei, Ni,Pi, Mi, and $r$, respectively, are technical cost, life expectancy of the system, mean number of operations for which the device has been used, purchase price, maintenance price and discount rate.

Reusable instruments comprised laparoscopic aortic, open aortic and peripheral vascular instruments. For the laparoscopic procedure, both laparoscopic and peripheral vascular instruments were used. For the open procedure, open aortic and peripheral vascular instruments were utilized. Costs related to laparoscopic trocars, clamps, and sutures were categorized under disposable instruments costs.
A life expectancy of 7 years for the laparoscopic devices was assumed. An accurate price for sterilization of instruments could not be attained. We had to rely on literature ${ }^{18}$ and assumed a cost of $20 €$ for the sterilization of instruments.

We assumed a maximum number of uses of the laparoscopic instruments (needle holder, retractors, etc.) to be 150 procedures and 400 for open and peripheral vascular instruments.

\section{Statistics}

Continuous variables were summarized by mean and $95 \%$ confidence interval and categorical variables with frequencies and percentage. Comparison between the two treatments groups was performed by using Mann-Whitney U-test for continuous variables and Fischer's exact test for categorical variables. Statistical significance was set at a 5\% level $(p<0.05)$. SPSS statistics version 25.0 (IBM corporation, Armonk, NY, USA) was used for statistical analysis.

\section{Participants}

Patients from three vascular surgery departments in the South Eastern region of Norway participated in the study.

\section{Ethical statement}

The study was approved by the Regional Committee for Medical and Health Research Ethics (REC, region southeast of Norway, registration number 2012/1367). The NLAST trial was registered at www.clinicaltrials.gov with registration number NCT01793662. The study was conducted in accordance with the Declaration of Helsinki. Since the substudy is a part of an ongoing trial, the unidentified study data will be made available online after completion of the main trial.

\section{Operative technique}

Both LABFB and OABFB procedures were performed in general anesthesia. All patients received an antibiotic prophylaxis before operation start. The operation started by bilateral free dissection of the femoral arteries in both procedures. The patients received intravenous heparin before aortic cross-clamping and wound drains at the end of surgery.

\section{LABFB}

A transperitoneal, prerenal approach was utilized. ${ }^{19,20}$ The patient was placed in a complete right lateral position by tilting 
the table $\left(45^{\circ}\right)$ and by placing a bolster under the patient. A total of six trocars (12 mm each) were placed at appropriate positions through the abdominal wall. ${ }^{21}$ Descending colon was mobilized towards the right side to achieve prerenal exposure of the infrarenal aorta. The left genital vein was used as a landmark for approaching the left renal vein. The infrarenal aorta was exposed by opening the surrounding lymphatic tissue and dissection was extended distally towards the common iliac artery. Under the laparoscopic vision, retroperitoneal tunnels were made along the iliac vessels. Proximal and distal laparoscopic aortic clamps were applied. The vascular prosthesis was introduced into the abdominal cavity through a trocar and the prosthetic limbs placed through the retroperitoneal tunnels to the respective groin wounds. After aortotomy, an end-to-side anastomosis was performed by two 3-0 polypropylene hemi-sutures and the aortic clamps were removed. $^{11}$

\section{OABFB}

A midline laparotomy was performed. Retroperitoneum overlying the infrarenal aorta was opened, and the small intestine was mobilized to the right side of the abdominal aorta. Retroperitoneal tunnels were made along the iliac vessels. A prosthetic graft was introduced, with its limbs placed in the retroperitoneal tunnels to the groin wounds. After aortic cross-clamping, aortotomy was performed and end-to-side anastomosis was performed with a continuous $3-0$ polypropylene suture.

The femoral artery anastomoses were in both types of procedures made in end-to-side-fashion with continuous 5-0 polypropylene. Peritoneum overlying the aorta and the aortic anastomosis was closed to avoid contact of the prosthesis with the intestine. The midline fascia was closed with continuous sutures and the skin wound with metal staples. Each groin wound was closed with continuous sutures in the subcutis and the skin adapted with metal staples.

\section{Results}

Seventy consecutive patients with AIOD, TASC II type $\mathrm{D}$ lesions, with a mean age of 63.7 years (range 46-76 years), were randomized to either OABFB $(\mathrm{N}=36)$ or LABFB $(\mathrm{N}=34)$ in the period from February 2013 to January 2018. Table 2 summarizes the patients' baseline characteristics. The study population comprised the patients referred to the vascular surgery departments at the three participating hospitals. Flowchart of the patient population randomized to either open or laparoscopic aortobifemoral bypass for the treatment of aortoiliac occlusive disease is presented in Figure 1.

One patient from the OABFB group did not wish to have treatment and dropped out after randomization. One patient, randomized to $\mathrm{LABFB}$, was excluded due to a heavily calcified infra and juxtarenal abdominal aorta and was considered not suitable for aortobifemoral bypass surgery. Another patient randomized to LABFB, due to other health conditions, could not be operated yet and has been considered as drop-out. One patient in the OABFB group died on the 2 nd postoperative day because of acute myocardial infarction. A total of ten patients, three patients in the LABFB and seven in the OABFB group, had complications which required one or more reoperations. Perioperative results of the treatments are presented in Table 3.

Based on the total budget for each department for the year 2016 and the total in-hospital stay days, the cost of a single day admission of the patients at the recovery unit and vascular surgery ward was calculated to be 5,484 $€$ and $2,399 €$, respectively. The calculated cost of treatment in these two departments is presented in Table 4.

The calculated mean cost of operative treatment in the operation theatre for the LABFB was 3,118 $€$ and for the OABFB 1,784 $€$. For the estimation of technology costs for laparoscopic instruments (optic, rack, light source, insufflator, and other accessories), we employed Equation 2. The technology cost of LABFB was $118.4 €$ more than the OABFB, and the cost of disposable instruments was $1,136 €$ higher for the former procedure (Table 5).

Sixty-seven patients were treated successfully, either with LABFB (32) or OABFB (35). The comparison of the treatment costs in these patients showed that the total cost of treatment in the LABFB was $19,798 €$ and $34,016 €$ for the OABFB. The in-hospital cost of LABFB was $14,218 €$ less than the OABFB within 30 postoperative days. The treatment costs at different departments are given in Figure 2. The main factor leading to less treatment costs was the shorter length of hospital stay in LABFB group (mean 5.3 days, 95\% CI 4.1-6.5) as compared to OABFB (mean 10.1 days, 95\% CI 7.5-12.6). However, in 57 patients (LABFB, $\mathrm{n}=28$ and OABFB, $\mathrm{n}=29$ ) without complications within 30 postoperative days, the mean treatment cost was $16,759 €$ for $\mathrm{LABFB}$ and $21,474 €$ for OABFB.

In ten patients, who had to be re-operated due to different complications, the mean length of hospital stay in the LABFB ( $n=3)$ was 13.7 days (range 5-19 days) and 23.6 
Table 2 Baseline characteristics of patients included in NLAST trial, treated either by totally laparoscopic or open aortobifemoral bypass procedure.

\begin{tabular}{|c|c|c|c|}
\hline Baseline charasterictics & Laparoscopy $(\mathbf{N}=34)$ & Open surgery $(N=36)$ & p-value \\
\hline $\begin{array}{l}\text { Age in years, mean } \\
(95 \% \mathrm{Cl})\end{array}$ & $62.8(60.3-65.2)$ & $64.5(62.5-67.0)$ & $0.32^{\mathrm{b}}$ \\
\hline Male gender n (\%) & $15(44)$ & $17(47)$ & $0.82^{\mathrm{a}}$ \\
\hline Current smoker n (\%) & $15(44)$ & $10(28)$ & $0.35^{\mathrm{a}}$ \\
\hline Hypertension n (\%) & $23(68)$ & $26(72)$ & $0.80^{\mathrm{a}}$ \\
\hline Diabetes mellitus n (\%) & $2(6)$ & $4(\mathrm{II})$ & $0.67^{\mathrm{a}}$ \\
\hline CHD n (\%) & $6(18)$ & $8(22)$ & $0.77^{\mathrm{a}}$ \\
\hline COPD n (\%) & $8(24)$ & $7(19)$ & $0.77^{\mathrm{a}}$ \\
\hline \multicolumn{4}{|l|}{ Fontaine classification n (\%) } \\
\hline Class 2B & $26(76)$ & $30(83)$ & \\
\hline Class 3 & $6(18)$ & $6(17)$ & \\
\hline Class 4 & $2(6)$ & 0 & \\
\hline Cerebrovascular disease $\mathrm{n}(\%)$ & $2(6)$ & $3(8)$ & $1.00^{\mathrm{a}}$ \\
\hline Previous PTA n (\%) & $14(4 \mid)$ & $12(33)$ & $0.62^{\mathrm{a}}$ \\
\hline Previous vascular surgery $\mathrm{n}(\%)$ & $3(9)$ & $3(8)$ & $1.00^{\mathrm{a}}$ \\
\hline
\end{tabular}

Notes: a'Fischers Exact Test, b'Mann-Whitney U-test.

Abbreviations: NLAST Norwegian laparoscopic aortic surgery; CHD, coronary heart disease; COPD, chronic obstructive pulmonary disease; PTA, percutaneous transluminal angioplasty; $\mathrm{Cl}$, confidence interval.

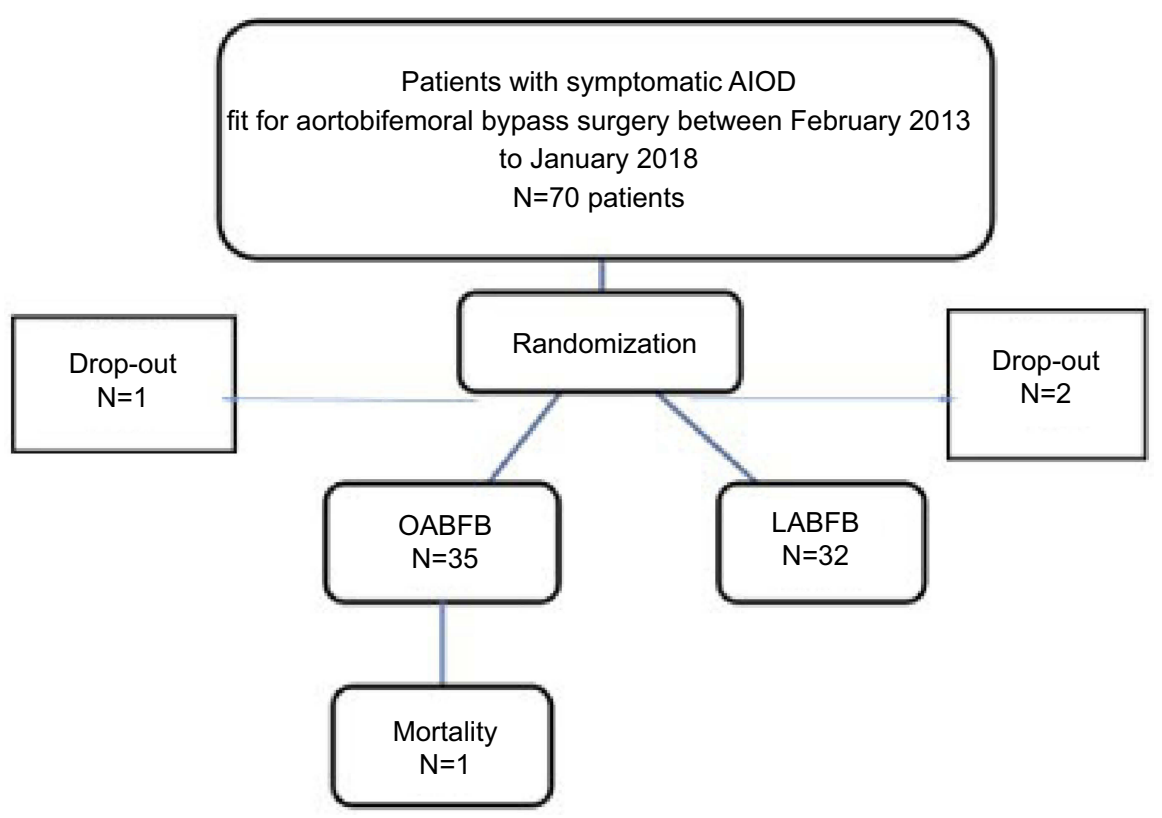

Figure I Flowchart for the patient population randomized for either open or laparoscopic aortobifemoral bypass for the treatment of TASC II type D lesions. Abbreviations: AIOD, aortoiliac occlusive disease; TASC II, Trans-Atlantic Inter-Society Consensus. 
Table 3 Perioperative outcomes of patients undergoing laparoscopic or open aortobifemoral bypass for the treatment of AIOD, TASC II type D lesions participating in NLAST.

\begin{tabular}{|l|l|l|l|}
\hline $\begin{array}{l}\text { Outcome } \\
\text { measures }\end{array}$ & $\begin{array}{l}\text { Laparocopy } \\
\mathbf{N}=32\end{array}$ & Open N=35 & p-value \\
\hline $\begin{array}{l}\text { Mean operation } \\
\text { time in minutes } \\
(95 \% \mathrm{Cl})\end{array}$ & $250(202-298)$ & $222(193-250)$ & $0.15^{\mathrm{a}}$ \\
\hline $\begin{array}{l}\text { Mean anesthesiol- } \\
\text { ogy time in minutes } \\
\text { (95\% Cl) }\end{array}$ & $309(294-328)$ & $265(244-28 \mathrm{I})$ & $0.00^{\mathrm{a}}$ \\
\hline $\begin{array}{l}\text { Mean post-opera- } \\
\text { tive stay at ICU in } \\
\text { days } \\
\text { (95\% Cl) }\end{array}$ & $1.3(0.9-1.7)$ & $2.5(\mathrm{I} .3-3.8)$ & $0.16^{\mathrm{a}}$ \\
\hline $\begin{array}{l}\text { Mean post-opera- } \\
\text { tive stay at hospital } \\
\text { in days (95\% Cl) }\end{array}$ & $5.3(4.1-6.5)$ & $10.1(7.5-12.6)$ & $0.00^{\mathrm{a}}$ \\
\hline $\begin{array}{l}\text { Reoperation during } \\
30 \text { Post-operative } \\
\text { days n (\%) }\end{array}$ & $3.0(4.5)$ & $7.0(\mathrm{I0.5)}$ & $0.25^{\mathrm{a}}$ \\
\hline $\begin{array}{l}30 \text { days mortality } \mathrm{n} \\
\text { (\%) }\end{array}$ & 0 & $\mathrm{I}(\mathrm{I.5)}$ & $0.34^{\mathrm{a}}$ \\
\hline
\end{tabular}

Notes: ${ }^{a}$ Mann-Whitney U-test.

Abbreviations: TASC II; Trans-Atlantic Inter-Society Consensus II NLAST; Norwegian Laparoscopic Aortic Surgery Trial, Cl; confidence interval. AIOD; Aortic iliac occlusive disease.

days (range 14-30 days) for the OABFB group $(n=7)$. The mean cost of treatment in the patients with reoperation in the LABFB group was $49,349 €$ and $82,985 €$ in the OABFB group.

\section{Discussion}

This is the first study conducted in a randomized fashion to perform a detailed evaluation of the treatment costs of LABFB and OABFB, during 30 postoperative days. This study shows that the LABFB has substantially less treatment costs $(14,218 €)$ as compared to OABFB. The main factor responsible for less treatment costs is shorter length of hospital stay in the LABFB group. We have in our previous randomized study found that the $\mathrm{LABFB}$ was more costeffective than the OABFB procedure. ${ }^{12}$ However, we had utilized national data for cost per day in hospital for the economic evaluations. ${ }^{22}$ The national data for cost per day in a somatic hospital is based on the average cost of a single hospital day in all the somatic hospital admissions. This left
Table 4 Total calculated treatment cost for the vascular surgery department and recovery unit at Oslo University Hospital, Aker for the year 2016

\begin{tabular}{|l|l|l|}
\hline & $\begin{array}{l}\text { Vascular } \\
\text { surgery } \\
\text { department } \\
\text { costs in } €\end{array}$ & $\begin{array}{l}\text { Recovery } \\
\text { unit } \\
\text { costs in } €\end{array}$ \\
\hline Personnel costs doctors & $2,765,654$ & $2,143,317$ \\
\hline Personnel costs other & $2,051,113$ & $3,244,961$ \\
\hline Total personnel costs for 2016 & $4,816,767$ & $5,388,279$ \\
\hline Indirect costs & $1,434,075.5$ & $1,319,121$ \\
\hline Total costs & $5,876,676$ & $6,707,400$ \\
\hline $\begin{array}{l}\text { Total patient hospital stay in days } \\
\text { (based on ward bed occupancy) }\end{array}$ & 2,450 days & 1,223 days \\
\hline Cost per day & 2,399 & 5,484 \\
\hline
\end{tabular}

a doubt if the cost per day from the national data was precise enough and representative for the patients undergoing aortobifemoral bypass surgery. In our present study, we have found that the cost of one day stay at hospital is $2,399 €$, which is higher than the national data cost for a single day hospital stay $(1,726 €)$.

Previously, in a non-randomized, retrospective singlecenter study, it was reported that the treatment costs were lower for $\mathrm{LABFB}$ as compared with OABFB for the treatment of aortoiliac occlusive disease. ${ }^{16}$ We have found in this study that operation theatre costs and technology cost for $\mathrm{LABFB}$ procedure are higher than OABFB. However, it would be imprecise to evaluate the two types of procedures based only on operation theatre costs. Reoperations often lead to increased length of hospital stay and thereby result in higher treatment costs. However, our calculations for the treatment of uncomplicated cases still shows that the LABFB costs less than the OABFB.

There are several limitations to the economic evaluation performed in this study. We have only performed an economic evaluation of the in-hospital costs and the other important factors, eg, patients and family resources and other economic losses in terms of job or sick-leave expenditures are not included in this economic evaluation. ${ }^{23}$

The actual personnel salary at the operation theatre can be higher than those included in this study. Besides, indirect costs for the operation theatre were not included in this economic 
Table 5 Calculated cost for reusable and disposable instruments for laparoscopic and open aortabifemoral bypass for the treatment of aortoiliac occlusive disease, Trans-Atlantic Inter-Society Consensus II

\begin{tabular}{|l|l|l|}
\hline Reusable instruments & Purchase price \\
\hline Open & $\begin{array}{l}\text { Peripheral aorta instruments } \\
\text { Abdominal aorta instruments }\end{array}$ & $\begin{array}{l}3,572 € \\
6,615 €\end{array}$ \\
\hline Laparoscopy & $\begin{array}{l}\text { Laparoscopic aorta instru- } \\
\text { ments } \\
\text { Peripheral aorta instruments }\end{array}$ & $26,882 €$ \\
\hline Reusable instruments & $\begin{array}{l}\text { Cost per } \\
\text { procedure }\end{array}$ \\
\hline Laparoscopic & $143.4 €$ \\
\hline Open & $25 €$ \\
\hline Difference & $118.4 €$ \\
\hline Disposable instruments & $\begin{array}{l}\text { Cost per } \\
\text { procedure }\end{array}$ \\
\hline Laparoscopy & $1,800 €$ \\
\hline Open & $664 €$ \\
\hline Difference & $1,136 €$ \\
\hline
\end{tabular}

Notes: I $€=9.3$ Nok in September 2017.

evaluation. Other limitations lie in the nature of the assumptions, for example, the lifetime of an instrument. However, even if it was possible to have an exact cost of these factors, it would not have affected our results since the main difference in the costs of the LABFB and OABFB is due to the longer hospital stay after the latter procedure. The actual salary of some categories of personnel could have been higher but that would have resulted in equal salary costs increase in the two procedure groups. It was not possible to estimate the time utilized by the recovery unit anesthesiologists outside of the recovery unit workload. This might have resulted in some lower costs for the recovery unit. The strength of this study lies in its randomized design and the finding of a substantial cost difference between the two procedures.

The standard for economic analysis is to be performed country-specifically. There are several differences between countries, not only with regards to prices and costs but also regarding organizational issues. A recent analysis by Woods B et al compared 183 different countries and found Norway to be among the five countries with the highest costs of acquiring health gains. ${ }^{24}$ Hence, conducting a similar analysis in most countries is likely to result in much lower cost differences, but would probably still be in favor of LABFB due to shorter hospital stay.

The identification of the consumed and saved resources in this study may have implications on the choice of treatment by the health providers, as well as for patients.

\section{Conclusion}

Laparoscopic aortobifemoral bypass for the treatment of aortoiliac occlusive disease costs less than the open aortobifemoral bypass procedure.

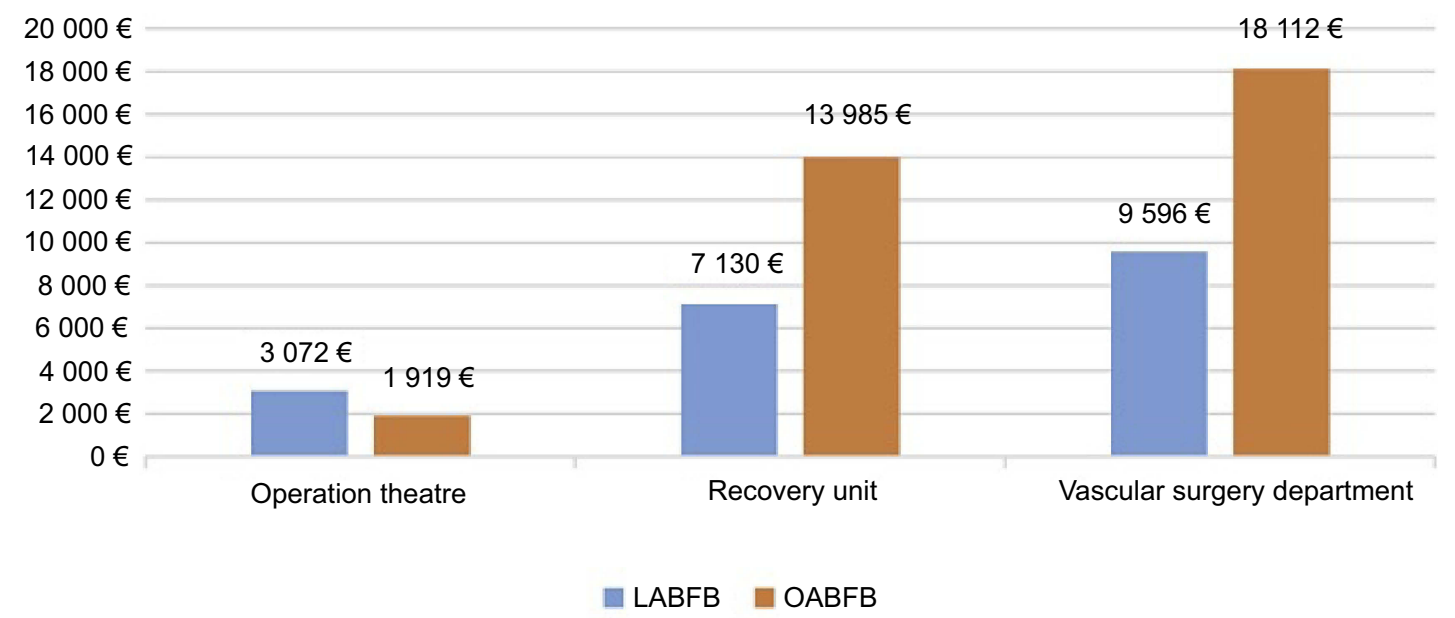

Figure 2 Cost distribution at different units for the patients treated with either LABFB or OABFB at Oslo University Hospital, Aker for the year 2016. Abbreviations: AIOD, aortoiliac occlusive disease; OABFB, open aortobifemoral bypass; LABFB, laparoscopic aortobifemoral bypass. 


\section{Acknowledgments}

We are thankful to the surgical staff at all the participating hospitals for helping us to conduct this study, and especially the economy department for providing us the economic data.

\section{Disclosure}

The authors report no conflicts of interest in this work.

\section{References}

1. Ricco JB, Thanh Phong L, Belmonte R, et al. Open surgery for chronic limb ischemia: a review. J Cardiovasc Surg (Torino). 2013;54(6):719-727.

2. Pulli R, Dorigo W, Fargion A, et al. Early and long-term comparison of endovascular treatment of iliac artery occlusions and stenosis. $J$ Vasc Surg. 2011;53(1):92-98. doi:10.1016/j. jvs.2010.08.034

3. Kim TH, Ko YG, Kim U, et al. Outcomes of endovascular treatment of chronic total occlusion of the infrarenal aorta. J Vasc Surg. 2011;53(6):1542-1549. doi:10.1016/j.jvs.2011.02.015

4. Norgren L, Hiatt WR, Dormandy JA, et al. Inter-Society Consensus for the Management of Peripheral Arterial Disease (TASC II). Eur J Vasc Endovasc Surg. 2007;33(Suppl 1):S1-75. doi:10.1016/j.ejvs.2006.09.024

5. Sachwani GR, Hans SS, Khoury MD, et al. Results of iliac stenting and aortofemoral grafting for iliac artery occlusions. J Vasc Surg. 2013;57(4):1030-1037. doi:10.1016/j.jvs.2012.09.038

6. Tshomba Y, Melissano G, Apruzzi L, Baccellieri D, Negri G, Chiesa R. Open repair for aortic occlusive disease: indication, techniques, results, tips and tricks. J Cardiovasc Surg (Torino). 2014;55(2 Suppl 1):57-68.

7. Ricco JB, Probst H. Long-term results of a multicenter randomized study on direct versus crossover bypass for unilateral iliac artery occlusive disease. J Vasc Surg. 2008;47(1):45-53; discussion 53-44. doi:10.1016/j.jvs.2007.08.050

8. Kazmi SS, Jorgensen JJ, Sundhagen JO, et al. A comparative cohort study of totally laparoscopic and open aortobifemoral bypass for the treatment of advanced atherosclerosis. Vasc Health Risk Manag. 2015;11:541-547. doi:10.2147/VHRM.S92671

9. Ricco JB, Cau J, Biancari F, et al. Outcome after open and laparoscopic aortic surgery in matched cohorts using propensity score matching. Eur J Vasc Endovasc Surg. 2016;52(2):179-188. doi:10.1016/j.ejvs.2016.02.021

10. Bruls S, Quaniers J, Tromme P, Lavigne JP, Van Damme H, Defraigne JO. Comparison of laparoscopic and open aortobifemoral bypass in the treatment of aortoiliac disease. Results of a contemporary series (2003-2009). Acta Chir Belg. 2012;112(1):51-58.
11. Coggia M, Javerliat I, Di Centa I, et al. Total laparoscopic bypass for aortoiliac occlusive lesions: 93-case experience. J Vasc Surg. 2004;40 (5):899-906. doi:10.1016/j.jvs.2004.08.013

12. Krog AH, Sahba M, Pettersen EM, Wisloff T, Sundhagen JO, Kazmi SS. Cost-utility analysis comparing laparoscopic vs open aortobifemoral bypass surgery. Vasc Health Risk Manag. 2017;13:217-224. doi:10.2147/VHRM.S138516

13. Wisloff T. Priority-setting criteria in the Norwegian health services. Tidsskr Nor Laegeforen. 2015;135(15):1373-1375. doi:10.4045/ tidsskr. 15.0228

14. Skeie B, Mishra V, Vaaler S, Amlie E. A comparison of actual cost, DRG-based cost, and hospital reimbursement for liver transplant patients. Transpl Int. 2002;15(9-10):439-445. doi:10.1007/s00147002-0430-0

15. Mishra V, Skeie B, Vaaler S, Amlie E. A comparison of actual registered costs and costs derived from diagnosis-related groups (DRGs) for patients undergoing heart transplantation, lung transplantation, and thoracotomy for other lung diseases. Transpl Int. 2001;14 (6):361-369. doi:10.1007/s001470100001

16. Rouers A, Meurisse N, Lavigne JP, et al. Potential benefits of laparoscopic aorto-bifemoral bypass surgery. Acta Chir Belg. 2005;105 (6):610-615.

17. Ismail I, Wolff $\mathrm{S}$, Gronfier A, Mutter D, Swanstrom LL, Swantröm LL. A cost evaluation methodology for surgical technologies. Surg Endosc. 2015;29(8):2423-2432. doi:10.1007/ s00464-014-3929-4

18. Yung E, Gagner M, Pomp A, Dakin G, Milone L, Strain G. Cost comparison of reusable and single-use ultrasonic shears for laparoscopic bariatric surgery. Obes Surg. 2010;20(4):512-518. doi:10.1007/s11695-008-9723-4

19. Cau J, Ricco JB, Corpataux JM. Laparoscopic aortic surgery: techniques and results. J Vasc Surg. 2008;48(6Suppl):37S-44S; discussion 45S. doi:10.1016/j.jvs.2008.08.033

20. Lin JC, Kolvenbach R, Schwierz E, Wassiljew S. Total laparoscopic aortofemoral bypass as a routine procedure for the treatment of aortoiliac occlusive disease. Vascular. 2005;13(2):80-83. doi:10.1258/rsmvasc. 13.2 .80

21. Kazmi SS, Sundhagen JO, Florenes TL, Kroese AJ, Jorgensen JJ. Laparoscopic aortic surgery. Tidsskr Nor Laegeforen. 2007;127 (11):1518-1520.

22. Huseby BMKB, Ødegaard H. SAMDATA Spesialist helsetjenesten 2014 (Data from Norwegian specialist health service). Available from: https://helsedirektoratet.no/Lists/Publikasjoner/Attachments/989/ SAMDATA\%202014\%20IS-2348.pdf. Accessed October 28, 2018.

23. Drummond MF, Sculpher MJ, Claxton K. Methods for the Economic Evaluation Og Health Care Programmes. Fourth ed. UK: Oxford University Press; 2015.

24. Woods B, Revill P, Sculpher M, Claxton K. Country-level cost-effectiveness thresholds: initial estimates and the need for further research. Value Health. 2016;19(8):929-935. doi:10.1016/j. jval.2016.02.017

\section{Publish your work in this journal}

The Open Access Journal of Clinical Trials is an international, peerreviewed, open access journal publishing original research, reports, editorials, reviews and commentaries on all aspects of clinical trial design, management, legal, ethical and regulatory issues, case record form design, data collection, quality assurance and data auditing methodologies. The manuscript management system is completely online and includes a very quick and fair peer-review system, which is all easy to use. Visit http://www.dovepress.com/testimonials.php to read real quotes from published authors. 